\title{
The Scientific Foundation for the Physical Activity Guidelines for Americans, 2nd Edition
}

\author{
Kenneth E. Powell, Abby C. King, David M. Buchner, Wayne W. Campbell, Loretta DiPietro, \\ Kirk I. Erickson, Charles H. Hillman, John M. Jakicic, Kathleen F. Janz, Peter T. Katzmarzyk, \\ William E. Kraus, Richard F. Macko, David X. Marquez, Anne McTiernan, \\ Russell R. Pate, Linda S. Pescatello, and Melicia C. Whitt-Glover
}

\begin{abstract}
Background: The 2018 Physical Activity Guidelines Advisory Committee Scientific Report provides the evidence base for the Physical Activity Guidelines for Americans, 2nd Edition. Methods: The 2018 Physical Activity Guidelines Advisory Committee addressed 38 questions and 104 subquestions selected for their public health relevance, potential to inform public policies and programs, maturity of the relevant science, and applicability to the general US population. Rigorous systematic literature searches and literature reviews were performed using standardized methods. Results: Newly described benefits of physical activity include reduced risk of excessive weight gain in children and adults, incidence of 6 types of cancer, and fall-related injuries in older people. Physical activity is associated with enhanced cognitive function and mental health across the life span, plus improved mental health and physical function. There is no threshold that must be exceeded before benefits begin to accrue; the accrual is most rapid for the least active individuals. Sedentary time is directly associated with elevated risk of all-cause and cardiovascular mortality, incident cardiovascular disease and type 2 diabetes, and selected cancer sites. A wide range of intervention strategies have demonstrated success in increasing physical activity. Conclusion: The 2018 Physical Activity Guidelines Advisory Committee Scientific Report provides compelling new evidence to inform physical activity recommendations, practice, and policy.
\end{abstract}

Keywords: public health, exercise, disease prevention, health promotion

Regular physical activity is associated with a wide range of health benefits. ${ }^{1}$ Unfortunately, only about $20 \%$ of adults and high school aged youth meet the current federal guidelines for both

Powell is retired from the Centers for Disease Control, Georgia Department of Public Health, Atlanta, GA. King is with the Departments of Health Research \& Policy (Epidemiology), and Medicine, School of Medicine, Stanford Prevention Research Center, Stanford University, Stanford, CA. Buchner is with the Department of Kinesiology and Community Health, University of Illinois at UrbanaChampaign, Champaign, IL. Campbell is with the Department of Nutrition Science, Purdue University, West Lafayette, IN. DiPietro is with the Department of Exercise and Nutrition Sciences, Milken Institute School of Public Health, The George Washington University. Washington, DC. Erickson is with the Departments of Psychology and Geriatric Medicine, University of Pittsburgh, Pittsburgh, PA. Hillman is with the Departments of Psychology and Physical Therapy, Movement, and Rehabilitation Sciences, Northeastern University, Boston, MA. Jakicic is with the Department of Health and Physical Activity, Physical Activity and Weight Management Research Center, University of Pittsburgh, Pittsburgh, PA. Janz is with the Departments of Health and Human Physiology and Epidemiology, University of Iowa, Iowa City, IA. Katzmarzyk is with Pennington Biomedical Research Center, Baton Rouge, LA. Kraus is with the Department of Medicine, School of Medicine, Duke University, Durham, NC. Macko is with the Departments of Neurology and Medicine and Geriatrics, School of Medicine, University of Maryland, Baltimore, MD. Marquez is with the Department of Kinesiology and Nutrition, University of Illinois at Chicago, Chicago, IL. McTiernan is with Fred Hutchinson Cancer Research Center, School of Medicine, School of Public Health, University of Washington, Seattle, WA. Pate is with the Department of Exercise Science, Arnold School of Public Health, University of South Carolina, Columbia, SC. Pescatello is with the Department of Kinesiology, College of Agriculture, Health and Natural Resources, University of Connecticut, Storrs, CT. Whitt-Glover is with Gramercy Research Group, Winston-Salem State University, Winston-Salem, NC. Powell (nekllewop@ hotmail.com) is corresponding author. Kenneth E. Powell and Abby C. King are co-first authors. aerobic and muscle-strengthening physical activity. ${ }^{2}$ In 2016, the US Department of Health and Human Services convened the 2018 Physical Activity Guidelines Advisory Committee (PAGAC) to review and summarize the current scientific evidence regarding the relationship between physical activity and health. The committee's report serves as the basis for the Physical Activity Guidelines for Americans, 2nd Edition, ${ }^{3}$ which updates the 2008 Physical Activity Guidelines for Americans. ${ }^{4}$ The 2008 PAGAC Scientific Report ${ }^{5}$ provided a fundamental starting point for allowing the 2018 Committee to examine more broadly the wide-ranging benefits of physical activity to health, as well as the types, volumes, and intensities of physical activity that are associated with those benefits.

New findings since the 2008 PAGAC Scientific Report ${ }^{5}$ substantially expand the list of health benefits that are attributable to physical activity. Moreover, the 2018 Scientific Report provides more specific knowledge about how to achieve those health benefits and demonstrates that physical activity promotion at the population level can be accomplished using a variety of strategies. This article summarizes the process and major findings of the 2018 PAGAG Scientific Report, ${ }^{1}$ with emphasis on topics not previously addressed in 2008. The full report is available at https://health.gov/ paguidelines/second-edition/report.aspx.

\section{Methods}

\section{Scope of Review}

The committee established 9 subcommittees based on current public health priorities and areas with new information since the 2008 PAGAC Scientific Report: (1) aging, (2) brain health, (3) cancer primary prevention, (4) cardiometabolic health and prevention of weight gain, (5) exposure, (6) individuals with 
chronic conditions, (7) promoting regular physical activity, (8) sedentary behavior, and (9) youth, as well as a pregnancy working group. Through a series of discussions and ranking procedures, the committee identified 38 questions and 104 subquestions to be addressed by the subcommittees (Supplementary Table S1 [available online]). Questions were selected for their public health relevance, potential to inform public policies and programs, maturity of the relevant science, and applicability to the general US population. Methodological details regarding question development, analytical frameworks, inclusion and exclusion criteria, and search strategies are available in the 2018 Scientific Report, ${ }^{6}$ the supplementary material to the report, ${ }^{7}$ and a peer-reviewed article. ${ }^{8}$

\section{Data Sources and Searches}

The review of the literature was assisted by a consulting services company through a contract with US Department of Health and Human Services. Three bibliographic databases (PubMed®, CINAHL, and Cochrane Library) were used for all searches, which included only studies of human subjects published in English in peer-reviewed journals or high-quality reports. The inclusion dates varied among questions (Supplementary Table S1 [available online]), most often depending on whether a similar question had been addressed by the 2008 PAGAC Report. ${ }^{5}$ All searches began with a search for systematic reviews, meta-analyses, pooled analyses, and high-quality reports such as the 2008 PAGAC Report. For a few questions, the committee expanded the search to include original research articles because the search for systematic reviews: (1) was insufficient to address the question at hand (excessive weight gain, children $<6 \mathrm{y}$, progression of osteoarthritis, relation of step counts and bout duration to health outcomes), (2) had captured experimental studies but not observational studies (fall-related injuries among older people), or (3) had not captured recently published original research known to be important (sedentary behavior). If the committee became aware of a relevant article that was not captured by the search, the search methods were examined to determine why the article had been missed, and if appropriate, the search was revised and repeated.

\section{Study Selection, Evidence Extraction, and Synthesis}

All titles and abstracts were reviewed by 2 subcommittee members. Discrepancies were resolved by discussion or by a third reviewer. Potentially relevant articles based on title and abstract underwent fulltext review by 2 subcommittee members. Articles that remained after title, abstract, and full-text review were examined in detail by 2 or more subcommittee members. Although procedures varied among subcommittees, subcommittee members generally extracted the most pertinent information into "working tables" (see, eg, https://health. gov/paguidelines/second-edition/report/supplementary_material/pdf/ Supplementary_Table_S-F2-1.pdf). Using standard procedures, the consulting service staff prepared extractions, which included the citation, search dates for systematic reviews, the abstract, and information about the exposure and the outcome. Information from these tables and from the ad hoc tables prepared by subcommittee members provided the foundation for committee discussions and conclusions.

\section{Strength of Evidence Assessment}

For every question and subquestion, each subcommittee presented a draft of its conclusions based on the available evidence to the full committee. This draft included information on the strength of the evidence supporting that conclusion and a summary of the underlying evidence. Evidence was graded as strong, moderate, limited, or not assignable based on a modification of the Assessment of

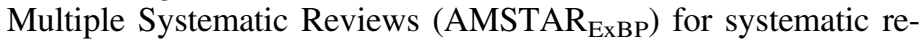
views, meta-analyses, and pooled analyses ${ }^{6,9,10}$; the US Department of Agriculture Nutrition Evidence Library Bias Assessment Tool for original research ${ }^{11,12}$; a tool created for the 2018 PAGAC for reports 6 ; and committee-developed procedures for grading the evidence based on 5 criteria: applicability, generalizability, risk of bias/study limitations, quantity and consistency, and magnitude and precision of effect (Supplementary Table S2 [available online]). The committee discussed, modified if appropriate, and gave final approval for all conclusions and strength of evidence assessments in public meetings.

\section{Results}

A total of 20,838 titles, 4,913 abstracts, and 2,139 full-text articles were evaluated; 837 unique articles met the criteria for inclusion. The number of included articles per question ranged from 2 to 96, with a median of 15 articles (Supplementary Table S1 [available online]). Operational definitions and methods for measuring physical activity varied considerably among the included articles. For the general adult population, self-reported leisure-time aerobic activity of moderate to vigorous intensity was the most prevalent domain reported in the available literature. Other domains (eg, occupational, transportation, household activity) were inconsistently available. Studies of device-measured physical activity (eg, accelerometer, pedometer) were uncommon, except for studies that examined the role of step counts, bout duration, and high-intensity interval training on health outcomes. For children $<6$ years of age, most studies utilized devicemeasured physical activity and included light-, moderate-, and vigorous-intensity activity. For older adults, most intervention studies used combinations of different types of activity (eg, aerobic, muscle strengthening, balance training), which tended to be of light to moderate intensity. Sedentary behavior was operationalized as time spent sitting, time spent watching television, or counts below a specified value on an accelerometer.

\section{The Health Benefits of Physical Activity}

The scientific evidence accumulated since the 2008 Scientific Report markedly expands the list of documented health benefits accruing to more physically active individuals. The most recent literature now includes evidence of (1) reduced risk of cancer of the bladder, endometrium, esophagus, kidney, lung, and stomach; (2) reduced risk of dementia; (3) reduced risk of excessive weight gain in children, adults, and pregnant women; (4) reduced risk of gestational diabetes and postpartum depression; and (5) reduced risk of fallrelated injuries in older people. In addition, there is evidence that physical activity is associated with (1) improved quality of life, (2) improved sleep; (3) reduced feelings of anxiety and depression in healthy people and in people with existing clinical syndromes, and (4) improved cognitive function across the life span. Regular physical activity improves bone health and weight status in children 3 to $<6$ years and physical function among older people regardless of frailty or existing chronic disease (Table 1). ${ }^{1}$ For individuals with 1 of 15 prevalent and diverse chronic conditions examined (eg, breast cancer, osteoarthritis, Parkinson's disease) 1 or more preventive health benefits were reported for those who were more physically active (Table 2). ${ }^{13-15}$ In the paragraphs below, we summarize 
Table 1 Physical Activity-Related Health Benefits for the General Population Documented by the 2008 and 2018 Physical Activity Guidelines Advisory Committees

\begin{tabular}{|c|c|}
\hline \multicolumn{2}{|l|}{ Children and youth } \\
\hline 3 to $<6$ y of age ${ }^{a}$ & Improved bone health and weight status \\
\hline $6-17$ y of age & $\begin{array}{l}\text { Improved cognitive function } \\
\text { Improved cardiorespiratory and muscular fitness } \\
\text { Improved bone health } \\
\text { Improved cardiovascular risk factor status } \\
\text { Improved weight status or adiposity } \\
\text { Fewer symptoms of depression }\end{array}$ \\
\hline \multicolumn{2}{|l|}{ Adults, all ages } \\
\hline All-cause mortality & Lower risk \\
\hline Cardiometabolic conditions & $\begin{array}{l}\text { Lower risk of cardiovascular disease and cardiovascular disease mortality (including } \\
\text { heart disease and stroke) } \\
\text { Lower risk of hypertension } \\
\text { Lower risk of type } 2 \text { diabetes }\end{array}$ \\
\hline Cancer & $\begin{array}{l}\text { Lower risk of bladder, breast, colon, endometrium, esophagus, kidney, stomach, } \\
\text { and lung cancers }\end{array}$ \\
\hline Brain health & $\begin{array}{l}\text { Reduced risk of dementia } \\
\text { Improved cognitive function } \\
\text { Improved cognitive function following acute bouts of aerobic activity } \\
\text { Improved quality of lifeImproved sleep } \\
\text { Reduced feelings of anxiety and depression in healthy people and in people with } \\
\text { existing clinical syndromes } \\
\text { Reduced risk of depression }\end{array}$ \\
\hline Weight status & $\begin{array}{l}\text { Reduced risk of excessive weight gain } \\
\text { An additive effect on weight loss when combined with moderate dietary restriction } \\
\text { Weight loss and the prevention of weight regain when a sufficient dose of moderate- } \\
\text { to-vigorous physical activity is attained }\end{array}$ \\
\hline \multicolumn{2}{|l|}{ Older adults } \\
\hline Falls & $\begin{array}{l}\text { Reduced risk of falls } \\
\text { Reduced risk of fall-related injuries }\end{array}$ \\
\hline Physical function & Improved physical function in older adults with and without frailty \\
\hline \multicolumn{2}{|c|}{ Women who are pregnant or postpartum } \\
\hline During pregnancy & $\begin{array}{l}\text { Reduced risk of excessive weight gain } \\
\text { Reduced risk of gestational diabetes } \\
\text { No risk to fetus from moderate-intensity physical activity }\end{array}$ \\
\hline During postpartum & Reduced risk of postpartum depression \\
\hline
\end{tabular}

Note: Benefits in bold are those added in 2018; benefits in regular font are those noted in the 2008 Scientific Report. ${ }^{5}$ Only outcomes with strong or moderate evidence of effect are included in the table.

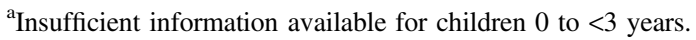

findings from 2 topic areas (brain health and weight gain) not previously addressed in the 2008 Scientific Report.

Brain Health. Brain health, an area of recent and rapid development, is positively affected by single bouts, as well as by regularly performed moderate- to vigorous-intensity physical activity (MVPA). In addition to reducing the risk of dementia, physical activity improves several components of cognition, including executive function (ie, the organization of everyday activities, planning for the future, and self-regulation of impulsive and sensation-seeking behaviors), memory, processing speed, attention, and academic performance. These performance improvements are supported by evidence from neuroimaging techniques demonstrating parallel changes in brain structure and function. ${ }^{16-20}$ The beneficial effects are observed across a variety of physical activities, including aerobic and strength training activity, and are reported in both healthy populations and in populations exhibiting cognitive deficits due to conditions such as schizophrenia, stroke, Parkinson's disease, and Alzheimer's disease. Improvements in cognitive performance are observed for up to an hour after a single bout of physical activity, with more sustained improvements observed with regular participation. ${ }^{13}$ MVPA also improves other aspects of brain health, such as symptoms of depression and anxiety among individuals with and without clinical depression or anxiety and perceived quality of life. ${ }^{13}$ In addition, both a single bout and regularly performed MVPA improve sleep quality, reduce sleep onset latency, increase time in deep sleep, improve sleep efficiency (the percentage of time actually sleeping), and reduce daytime sleepiness. ${ }^{13}$ Moreover, it does not seem to matter whether the activity is performed more than 8 hours, 3 to 8 hours, or less than 3 hours before bedtime. ${ }^{21}$

Prevention of Weight Gain. Excessive weight gain is less common among children and adults (including pregnant women) who are more physically active, ${ }^{22-24}$ with greater amounts of physical activity associated with a lower risk of significant weight gain or development of obesity (Figure 1). ${ }^{25}$ For people with overweight or obesity, the relative risk reduction in all-cause mortality, cardiovascular disease 
Table 2 Physical Activity-Related Health Benefits for Individuals with a Chronic Condition Documented by the 2008 and 2018 Physical Activity Guidelines Advisory Committees

\begin{tabular}{|c|c|}
\hline Breast cancer $^{\mathrm{a}}$ & Reduced risk of all-cause and breast cancer mortality \\
\hline Colorectal cancer $^{\mathrm{a}}$ & Reduced risk of all-cause and colorectal cancer mortality \\
\hline Prostate cancer ${ }^{\mathrm{a}}$ & Reduced risk of prostate cancer mortality \\
\hline \multirow[t]{2}{*}{ Osteoarthritis $^{\mathrm{b}}$} & Decreased pain \\
\hline & Improved function and quality of life \\
\hline Hypertension $^{\mathrm{b}}$ & $\begin{array}{l}\text { Reduced risk of progression of cardiovascular disease } \\
\text { Reduced risk of increased blood pressure over time }\end{array}$ \\
\hline Type 2 diabetes ${ }^{\mathrm{b}}$ & $\begin{array}{l}\text { Reduced risk of cardiovascular mortality } \\
\text { Reduced progression of disease indicators: hemoglobin A1c, } \\
\text { blood pressure, blood lipids, and body mass index }\end{array}$ \\
\hline Recent hip fracture $^{c}$ & Improved walking, balance, and activities of daily living \\
\hline Frailty $^{\mathrm{c}}$ & Improved walking, balance, and activities of daily living \\
\hline Stroke $\mathrm{c}^{\mathrm{c} d}$ & $\begin{array}{l}\text { Improved walking, physical fitness, functional independence } \\
\text { Improved cognition }\end{array}$ \\
\hline \multirow[t]{2}{*}{ Spinal cord injury ${ }^{b}$} & Improved physical fitness \\
\hline & Improved walking and wheel chair skills \\
\hline Dementia $^{\mathrm{d}}$ & Improved cognition \\
\hline \multirow[t]{2}{*}{ Multiple sclerosis ${ }^{\mathrm{b}, \mathrm{d}}$} & Improved walking \\
\hline & Improved strength and physical fitness \\
\hline Parkinson's disease ${ }^{\mathrm{c}, \mathrm{d}}$ & Improved walking, balance, activities of daily living, and cognition \\
\hline Schizophrenia $^{\mathrm{d}}$ & Improved quality of life and cognition \\
\hline Attention deficit hyperactivity disorder ${ }^{\mathrm{d}}$ & Improved cognition \\
\hline
\end{tabular}

Note: Benefits in bold are those added in 2018 ; benefits in normal font are those noted in the 2008 Scientific Report. ${ }^{5}$ Only outcomes with strong or moderate evidence of effect are included in the table. Outcomes assessed varied by chronic condition.

${ }^{a}$ Mortality and disease progression outcomes. ${ }^{b}$ Mortality, development of new chronic condition, quality of life, physical function, and progression of disease. ${ }^{c}$ Physical function only. ${ }^{\mathrm{d}}$ Cognition.

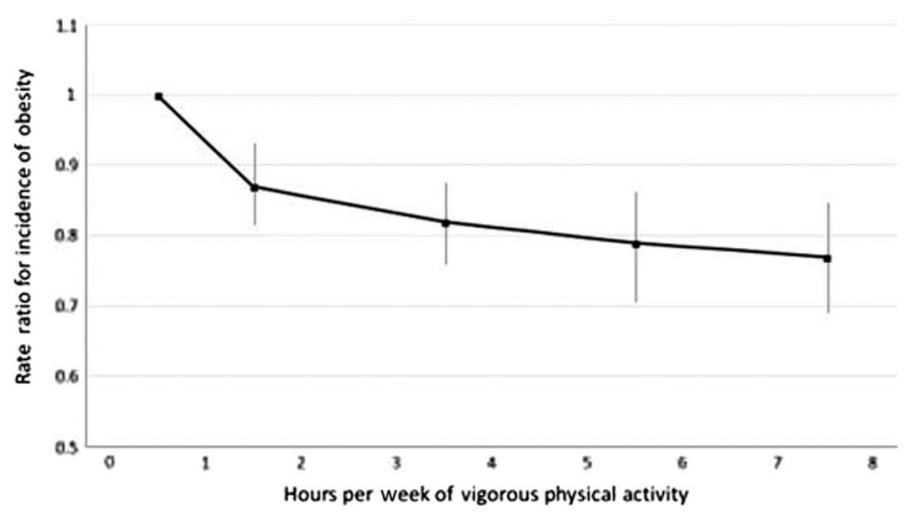

Figure 1 - Inverse dose-response relationship between risk of developing obesity and volume of vigorous physical activity. Adapted from data found in Rosenberg et al. ${ }^{25}$

incidence and mortality, and incidence of type 2 diabetes is similar to that experienced by people with normal body weight. ${ }^{1}$

\section{Characteristics of Physical Activity Associated With Benefits}

The Dose-Response Relationship Between Physical Activity and Health. All reviews reported an inverse relationship between self-reported MVPA and all-cause mortality, cardiovascular disease mortality and incidence, and incidence of type 2 diabetes; analyses comparing 3 or more physical activity exposure categories consistently reported an inverse, curvilinear dose-response relationship (Figure 2). 1,22,26-29 The response curves demonstrate that when the least active individuals add even small amounts of activity to their daily routine, (1) there is no threshold that must be exceeded before benefits begin to accrue (ie, the reduction in risk begins with the addition of any amount of MVPA), (2) the slope of risk decline is steepest for the least active individuals, and (3) the reduction in risk continues across the full range of commonly achieved volumes, although the slope diminishes with increasing levels of MVPA.

Sedentary Behavior. There is a direct relationship between sedentary behavior and all-cause and cardiovascular disease mortality, incidence of cardiovascular disease, and type 2 diabetes, as well as the incidence of endometrial, colon, and lung cancers. ${ }^{30}$ The dose-response curves illustrate a direct relationship between both total sitting time and television viewing time and all-cause mortality (Figure 3).

Interaction Between Sitting Time and MVPA. Mortality risk is higher for longer versus shorter sitting times; however, this risk difference diminishes as the amount of MVPA increasesespecially among those reporting the greatest volume of MVPA (Figure 4). ${ }^{31}$ Compared with the referent group (most MVPA [top quartile] and lowest sitting time $[<4 \mathrm{~h} / \mathrm{d}]$ ), individuals with the least MVPA (bottom quartile) and most sitting time ( $>8 \mathrm{~h} / \mathrm{d}$ ) have the 


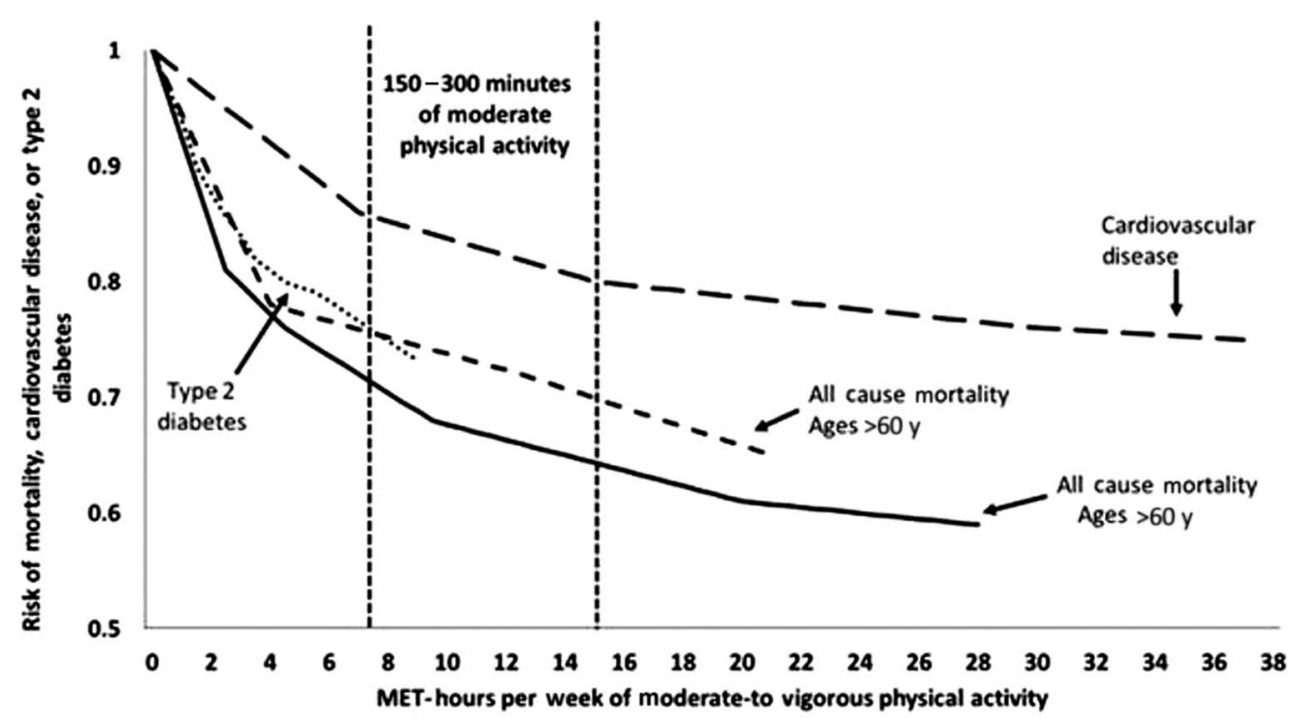

Figure 2 - Inverse dose-response relationships between self-reported aerobic moderate-to-vigorous physical activity and risk of all-cause mortality, risk of cardiovascular disease, and risk of type 2 diabetes. Source: risk of all-cause mortality adapted from Moore et al, ${ }^{26}$ risk of all-cause mortality among participants $>60$ years of age adapted from Hupin et al, ${ }^{27}$ risk of cardiovascular disease adapted from Sattelmair et al, ${ }^{28}$ and risk of type 2 diabetes adapted from 2018 PAGAC. ${ }^{22}$
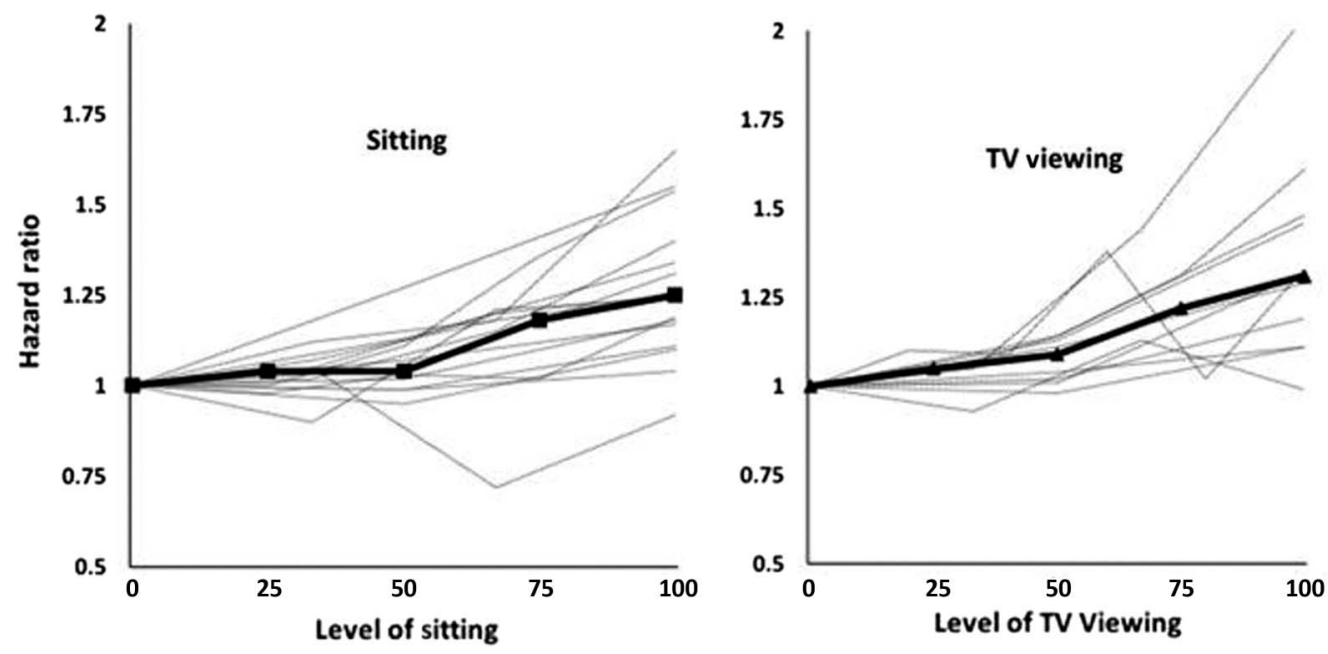

Figure 3 - Direct dose-response associations between sitting time and TV viewing time with all-cause mortality. The hazard ratio for studies with mortality rates for at least 3 levels of sitting or TV viewing time. The original categories of sitting (tertiles, quartiles, quintiles, etc) have been rescaled from 0 to 100 using an ordinal scale. For example, for a study with tertiles, the points are plotted at 0,50 , and 100 . Thick lines are median estimates of risk of all-cause mortality for sitting and TV time. Source: Panels A and B adapted from 2018 PAGAC. ${ }^{30}$ TV indicates television.

highest risk of all-cause mortality $(1.59,95 \%$ confidence interval $1.52-1.66)$. By contrast, individuals who are in the bottom quartile of MVPA but who report the least sitting time $(<4 \mathrm{~h} / \mathrm{d})$ are at elevated risk $(1.27,95 \%$ confidence interval $1.22-1.30)$, but only about half that of those who sit the most. For individuals reporting the greatest volume of MVPA (an estimated 35-38 metabolic equivalent-h/wk), the excess risk of mortality for different strata of sitting essentially disappears.

Sedentary time, light physical activity, and MVPA interact within a finite, 24-hour day. A heat map developed by the 2018 PAGAC committee depicts the risk of all-cause mortality associated with various combinations of sitting time (in hours) and
MVPA (in minutes) (Figure 5). The heat map was derived from regression techniques to interpolate the hazard ratios between 4 levels of sitting time and 4 levels of MVPA based on a harmonized meta-analysis of Ekelund et al. ${ }^{31} \mathrm{We}$ have assumed that for any given level of MVPA, the time spent sitting and the time spent in light-intensity activity (eg, walking about, light housework) are reciprocal. High sitting time is associated with low light-intensity time and low sitting time is associated with high light-intensity activity. As indicated by the heat map: (1) at low levels of MVPA, replacing sitting time with light-intensity activity reduces risk of premature mortality, (2) MVPA is necessary to achieve the greatest risk reduction, (3) for an equivalent reduction 


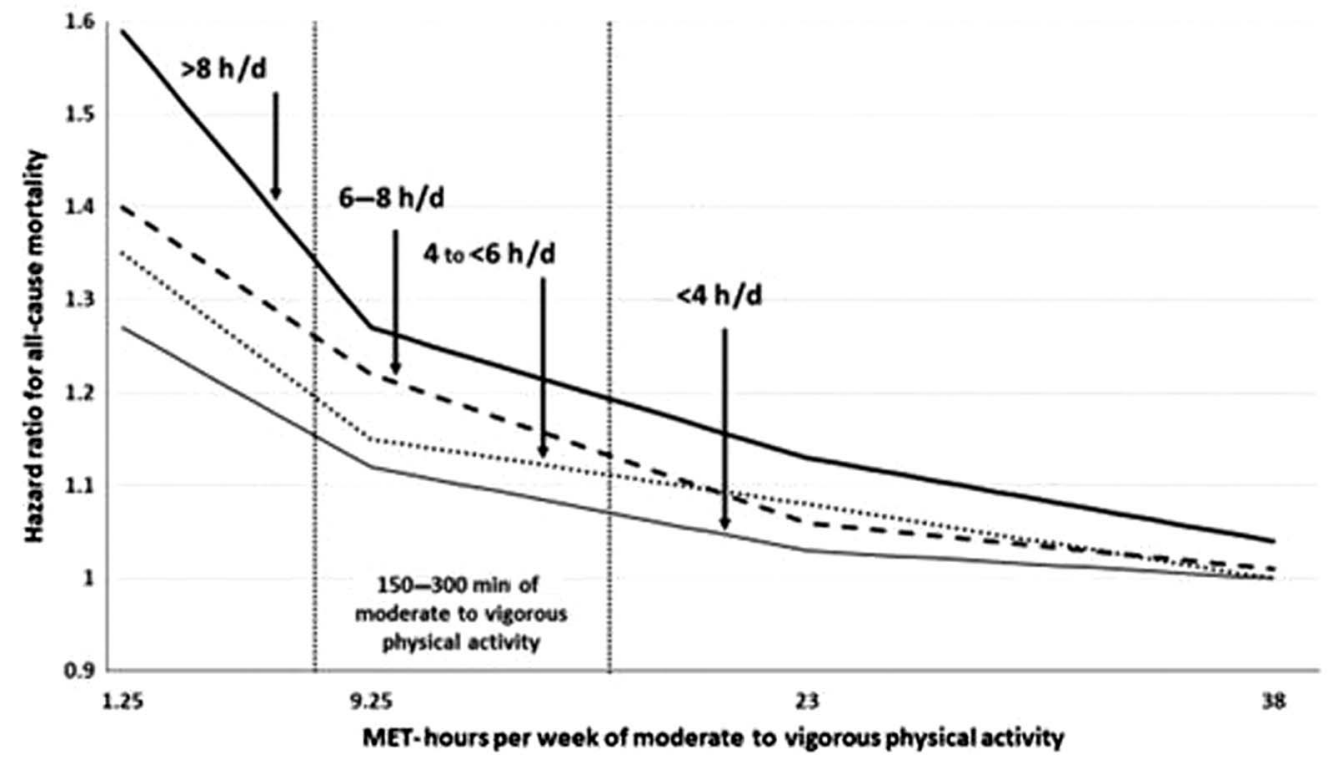

Figure 4 - Interaction between sitting time and volume of moderate-to-vigorous physical activity demonstrated by the reduction in risk associated with sitting time and TV viewing time at increasing volumes of moderate-to-vigorous physical activity. Adapted from 2018 PAGAC. ${ }^{30}$ The figure was developed from data presented in Ekelund et al. ${ }^{31} \mathrm{TV}$ indicates television.

in risk, increasing MVPA requires appreciably less time per day than increasing light-intensity activity, and (4) at the highest levels of MVPA (an estimated 35-38 metabolic equivalent-h/wk), the time spent sitting has a negligible effect on mortality risk.

Bout Length of MVPA. Recent research using device-measured physical activity and assessing a variety of cardiometabolic health indicators indicates that bouts of MVPA of any length (ie, time duration) contribute to the health benefits associated with the

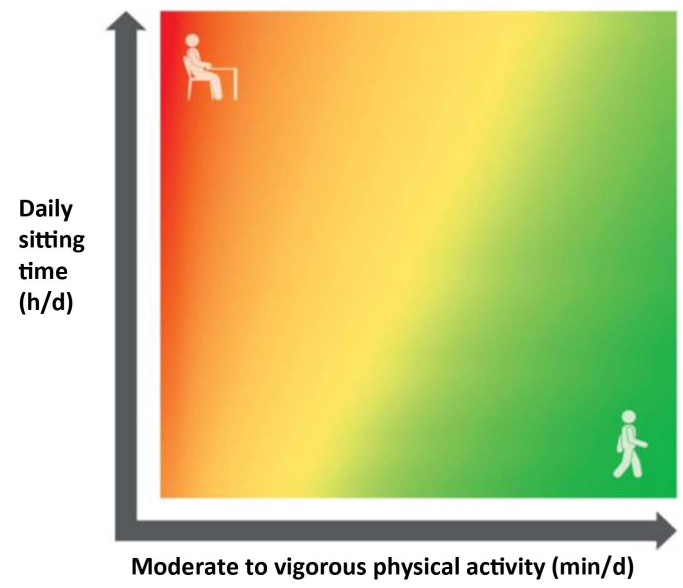

Figure 5 - Relationship among moderate-to-vigorous physical activity, sitting time, and risk of all-cause mortality. The risk of allcause mortality declines moving from high sitting and low moderate-tovigorous physical activity (dark gray color [red color in Online version], high risk) to low sitting and high moderate-to-vigorous physical activity (light gray color [green color in Online version], low risk). Replacing sitting time with light-intensity physical activity moves down the vertical axis; adding moderate-to-vigorous physical activity moves rightward along the horizontal axis. Source: 2018 Physical Activity Guidelines Advisory Committee. ${ }^{1}$ The figure was developed from data presented in Ekelund et al. ${ }^{31}$ accumulated total volume of physical activity. ${ }^{32-46}$ Of 40 comparisons within 14 studies, $78 \%$ (31 comparisons) indicated that bouts $<10$ minutes long were as good or better than bouts $\geq 10$ minutes. $^{1}$ An additional 10\% (4 comparisons) reported that bouts $<10$ minutes long were associated with risk reduction but did not make a direct comparison with bouts $\geq 10$ minutes.

\section{Strategies for Promoting Physical Activity}

Numerous intervention strategies, delivered through diverse communication channels and aimed at multiple population sectors and demographic subgroups, have been effective in increasing physical activity (Table 3). ${ }^{47}$ They include interventions aimed at individuals, interventions delivered in community settings, and programs delivered through a range of information and communication technology channels; elements of the built environment are also associated with increased physical activity. Although a number of interventions have small effect sizes (ie, $d$ in the range of $0.2-$ $0.4),{ }^{47}$ some, such as telephone-assisted advice and support and mobile phone interventions, have produced effect sizes in the medium range or stronger (ie, $d \geq 0.5$ ). ${ }^{48,49}$ Some sedentary behavior worksite interventions that targeted physical changes to work stations (eg, sit-stand workstations) have also had medium to large effect sizes (ie, $d \geq 0.5$ ). ${ }^{50}$

\section{Discussion}

This study provides an overview of the process used to develop the 2018 PAGAC Scientific Report and highlights topic areas not addressed in the 2008 Report (eg, brain health, prevention of weight gain, sedentary behavior, aspects of physical activity dose, new strategies for promoting physical activity). The benefits of physical activity include a reduced risk of many of the most common, severe, and expensive health outcomes (eg, heart disease, stroke, hypertension, dementia, type 2 diabetes, cancer, depression, and fall-related injuries in older adults). Benefits and risk 
Table 3 Selected Types of Interventions Shown to Increase Physical Activity or Reduce Sedentary Behavior

\begin{tabular}{|c|c|}
\hline Social ecological level & Type of physical activity intervention \\
\hline \multirow[t]{3}{*}{ Individual } & Interventions targeting youth, particularly if families are incorporated \\
\hline & Behavior theory-based interventions aimed at adults and older adults \\
\hline & Peer-led behavioral self-management interventions for older adults and individuals with chronic disease \\
\hline \multirow[t]{3}{*}{ Community } & Community-wide interventions including intensive contact with a majority of targeted population \\
\hline & School-based interventions that aim to increase physical activity during physical education classes \\
\hline & $\begin{array}{l}\text { Multicomponent school-based interventions aimed at increasing } \\
\text { student physical activity throughout the school day }\end{array}$ \\
\hline \multirow{6}{*}{$\begin{array}{l}\text { Communication } \\
\text { environment }\end{array}$} & Wearable activity monitors in combination with goal setting and other behavioral strategies \\
\hline & Telephone-assisted interventions in the general adult population including older adults \\
\hline & Internet-delivered interventions that include educational components \\
\hline & Computer-tailored print interventions in the general adult population \\
\hline & Mobile phone programs that include text messaging for adults \\
\hline & Smartphone applications for children and adolescents \\
\hline \multirow{4}{*}{$\begin{array}{l}\text { Physical environment } \\
\text { and policy }\end{array}$} & Point-of-decision prompts to use stairs versus escalators or elevators \\
\hline & $\begin{array}{l}\text { Built environment infrastructure and elements to enable active transport and } \\
\text { support recreational physical activity among children and adults }\end{array}$ \\
\hline & Access to parks and outdoor or indoor recreational facilities for children and adults \\
\hline & Interventions to reduce sedentary behavior \\
\hline \multirow[t]{2}{*}{ Community } & $\begin{array}{l}\text { School-based interventions that aim to reduce television viewing and other screen time behaviors through } \\
\text { counseling, parental involvement, tailored feedback, and use of screen allowance devices at home }\end{array}$ \\
\hline & Worksite interventions targeting sedentary behavior including physical changes to workstations \\
\hline
\end{tabular}

reductions were observed across the entire age spectrum. People with established chronic conditions also receive preventive health benefits (eg, reduced risk for other conditions, improved physical function). In addition to the range of health benefits listed in Tables 1 and 2, more physically active people of all ages enjoy greater physical function, enabling them to conduct their daily lives with more energy and without undue fatigue. ${ }^{1}$ Indeed, the array of physical, mental, and functional health benefits conferred by regular physical activity establish it as both a "best buy in public health" 51 and a worthy prescription tool for clinicians.

For the past 10 years, the federally recommended guidelines for physical activity have been 150 to 300 minutes per week of moderate-intensity activity, 75 to 150 minutes per week of vigorous-intensity activity, or an equivalent mixture of both. Those people performing this recommended volume of activity or more achieve substantial health benefits. ${ }^{1,5}$ Less well appreciated, however, is that the $30 \%$ to $50 \%$ of US adults ${ }^{52}$ who perform little or no MVPA can achieve some valuable health benefits by performing MVPA in amounts below the target range or by substituting light-intensity physical activity for sitting time. The interactions observed among sedentary time, light-intensity physical activity, and MVPA over the course of the day provide additional flexibility in the ways that physical activity behaviors can be modified to reduce the risk of all-cause mortality and other chronic conditions. This added flexibility in achieving federal guidelines for physical activity may be a good way for some people to begin increasing the overall volume of their weekly physical activity. ${ }^{5}$

The curvilinear, inverse dose-response relationship between physical activity and health was previously described in 2008 only for all-cause mortality. ${ }^{5}$ The most recent 2018 PAGAC Scientific Report now provides evidence of similarly shaped curves for cardiovascular mortality and incidence, as well as for the incidence of type 2 diabetes. ${ }^{22,29}$ There is insufficient information to depict dose-response curves for other health benefits at this time. It seems likely that the dose-response curves will be similarly shaped, although the maximal reductions in risk may be greater or lesser and may be reached at greater or lesser volumes of activity.

The social ecological model has been used as a framework for conceptualizing, studying, and implementing interventions to improve health behaviors, including physical activity. This model posits that health behaviors are influenced not only by person-level characteristics but also a broad range of social, community, and societal factors as well. Physical activity interventions, operating at all levels of the social ecological model, have been tested and found to be effective in increasing physical activity. ${ }^{47}$ In recent literature, many of the successful approaches have been directed toward individuals via specific channels, such as telephone-based advice and support, text messaging, smartphone apps, and other forms of electronic communication. The explosion of physical activityrelevant information and novel communication technologies provides an unprecedented opportunity to expand the reach, the tailored "touch," and the sustained impact of interventions to those who could benefit most. In addition, a large amount of evidence indicates that activity-friendly physical and social environments are associated with more physically active lifestyles across age groups, settings (school, workplace), and different forms of activity (recreation, active transport). Because effect sizes for specific interventions have been modest, it is likely that multiple strategies operating at all levels of the social ecological model will be needed to shift the population's current physical activity behaviors to healthier levels. Thus, interventions that produce only modest change by themselves may contribute importantly to larger cumulative efforts. ${ }^{53}$ 
Table 4 Leading Causes of Death, Most Prevalent Chronic Conditions, and Most Expensive Medical Conditions for Which Greater Participation in Physical Activity Would Be Expected to Reduce Incidence, Prevalence, and Expense Indicated by Shading and Bold Type

\begin{tabular}{|c|c|c|}
\hline Ten leading causes of death ${ }^{54}$ & Ten most prevalent chronic conditions ${ }^{55}$ & Ten most expensive medical conditions ${ }^{56}$ \\
\hline Heart disease & Hypertension & Heart conditions \\
\hline Cancer & Hyperlipidemia & Trauma disorders ${ }^{\mathrm{a}}$ \\
\hline Chronic lung diseases & Upper respiratory conditions $^{\text {b }}$ & Cancer \\
\hline Unintentional injuries $^{\mathbf{a}}$ & Arthritis & Mental disorders \\
\hline Stroke & Mood disorders & Asthma/COPD \\
\hline Alzheimer's disease & Diabetes & Hypertension \\
\hline Diabetes & Anxiety disorders & Type 2 diabetes \\
\hline Influenza and pneumonia & Asthma & Arthritis \\
\hline Kidney disease & Coronary artery disease & Back problems \\
\hline Suicide & Thyroid disorders & Healthy childbirth \\
\hline
\end{tabular}

Note: Conditions in bold and shaded cells are favorably influenced by greater participation in regular physical activity.

${ }^{\mathrm{a}}$ Includes falls. ${ }^{\mathrm{b}}$ Includes allergies and sinusitis.

\section{Conclusion}

In sum, findings from the 2018 Scientific Report underscore the public health impact of increasing population levels of regular physical activity and provide a firm foundation for the development of federal physical activity guidelines for the general US population. The list of health benefits attributable to greater amounts of physical activity continues to grow longer and applies to all segments of the US population. The public health burden associated with insufficient physical activity is substantial. Many of the most common causes of death, most prevalent chronic conditions, and most expensive medical conditions in the United States are favorably influenced by regular participation in physical activity (Table 4). ${ }^{54-57}$ Thus, even small increases in regular MVPA, especially if made by the least physically active individuals, would appreciably reduce the burden and cost of disease in the United States. More difficult to quantify are the physical activity benefits associated with improved cognition, better perceived quality of life, fewer symptoms of depression and anxiety, enhanced quality of sleep, and improved physical function across the full life span. Yet, these are the benefits that affect everyone on a daily basis and contribute not only to greater life satisfaction but also to enhanced productivity and fewer visits to health care providers. ${ }^{55,58}$

\section{Acknowledgments}

The authors would like to thank the following who served as Consultants to the committee: Matthew P. Buman, PhD (Arizona State University); David E. Conroy, PhD (The Pennsylvania State University, University Park, PA); Kelly Evenson, PhD (University of North Carolina-Chapel Hill, Chapel Hill, NC); Christine M. Friedenreich, PhD (University of Calgary, Alberta, Canada); William L. Haskell, PhD (Stanford University, Stanford, CA); Virginia Byers Kraus, MD, PhD (Duke University School of Medicine, Durham, NC); Melissa A. Napolitano, PhD (The George Washington University, Washington, DC); Steven J. Petruzzello, PhD (University of Illinois at Urbana-Champaign, Urbana, IL); and Ronald J. Sigal, MD (University of Calgary, Alberta, Canada). Outside experts to the committee: Katherine Brooke-Wavell, $\mathrm{PhD}$ (Loughborough University, Loughborough, UK); Alison N. Cernich, PhD (Eunice Kennedy-Shriver National Institute for Child Health and Human Development, Bethesda,
MD); Lisa Chasan-Tabor, ScD (University of Massachusetts, Amherst, MA); Tim Church, MD, PhD (ACAP Health Consulting); Janet E. Fulton, $\mathrm{PhD}$ (Centers for Disease Control and Prevention, Atlanta, GA); William L. Haskell, PhD (Stanford University, Stanford, CA); Wendy M. Kohrt, $\mathrm{PhD}$ (University of Colorado Denver, Aurora, CO); Heather McKay, $\mathrm{PhD}$ (University of British Columbia, Vancouver, BC); Richard P. Troiano, $\mathrm{PhD}$ (National Institutes of Health, Bethesda, MD); Jonathan Tobias, MD, $\mathrm{PhD}$ (University of Bristol, Bristol, UK); and Pedro F. Saint-Maurice, PhD (National Cancer Institute, Bethesda, MD). Co-Executive secretaries for the committee: Richard D. Olson, MD (Division of Preventive Science, Office of Disease Prevention and Health Promotion); Katrina L. Piercy, $\mathrm{PhD}$ (Physical Activity and Nutrition Advisor, Office of Disease Prevention and Health Promotion); Rachel M. Ballard, MD (Office of Disease Prevention, National Institutes of Health); Janet E. Fulton, PhD (Physical Activity and Health Branch, Division of Nutrition, Physical Activity, and Obesity, Centers for Disease Control and Prevention); Deborah A. Galuska, PhD (Associate Director for Science, Division of Nutrition, Physical Activity, and Obesity, Centers for Disease Control and Prevention); Shellie Y. Pfohl, MS (through September, 2016, President's Council on Fitness, Sports, \& Nutrition); Richard P. Troiano, PhD (Division of Cancer Control and Population Sciences, National Cancer Institute, National Institutes of Health). Lead management staff for HHS: Stephanie M. George, PhD (Office of Disease Prevention, National Institutes of Health); Alison Vaux-Bjerke, MPH (Office of Disease Prevention and Health Promotion). Management support staff for HHS: Emily Bhutiani, MS (National Cancer Institute, National Institutes of Health through June 2017); Eric Hyde, MPH (Division of Nutrition, Physical Activity, and Obesity, Centers for Disease Control and Prevention); Kate Olscamp, MPH (President's Council on Fitness, Sports \& Nutrition); Sarah Prowitt, MPH (Office of Disease Prevention and Health Promotion); Julia Quam, MSPH (Office of Disease Prevention and Health Promotion); Kyle Sprow, MPH (National Cancer Institute, National Institutes of Health). Data assistance staff for HHS: Susan A. Carlson, $\mathrm{PhD}$ (Division of Nutrition, Physical Activity, and Obesity, Centers for Disease Control and Prevention); Geoffrey Whitfield, PhD (Division of Nutrition, Physical Activity, and Obesity, Centers for Disease Control and Prevention). Technical writer/editor: Anne Brown Rodgers, HHS Consultant. ICF literature review staff, leadership team: Bonny Bloodgood, MA; Audie Atienza, $\mathrm{PhD}$; Sondra Dietz, MA; Isabela Lucas, PhD; Mary Schwarz, Bethany Tennant, PhD; Andrea Torres, PhD; and ICF librarians, abstractors, and additional support staff. Technical assistance to subcommittees: 
Tim Hughes and Susanne DeSantis (The George Washington University); Jamie Cohen, Katherine Collins, George Grove Jr, and Chelsea Stillman, $\mathrm{PhD}$ (University of Pittsburgh); David Bartlett, PhD (Duke University); Andrew Hua, PhD (University of Illinois at Urbana-Champaign); Benjamin Chrisinger, $\mathrm{PhD}$, and Darlyne Esparza (Stanford University); Janna Borden and Michaela Schenkelberg (University of South Carolina); and Jessica Goyette-Blankenship (Purdue University). The committee's work was supported by the US Department of Health and Human Services (HHS). Committee members were reimbursed for travel and per diem expenses for the 5 public meetings; committee members volunteered their time. HHS staff provided general administrative support to the committee and ensured that the committee adhered to the requirements for Federal Advisory Committees. HHS also contracted with ICF, a global consulting services company, to provide technical support for the literature searches conducted by the committee. HHS and ICF staff collaborated with the committee in the design and conduct of the searches by assisting with the development of the analytical frameworks, inclusion/exclusion criteria, and search terms for each primary question; using those parameters, ICF performed the literature searches. HHS and ICF had no role in the selection of questions, in the analysis and interpretation of the data, in the preparation, review, or approval of the manuscript, and in the decision to submit the manuscript for publication. Dr. Jakicic received an honorarium for serving on the Scientific Advisory Board for Weight Watchers International and was a co-investigator on a grant awarded to the University of Pittsburgh by Weight Watchers International.

\section{References}

1. 2018 Physical Activity Guidelines Advisory Committee. 2018 Physical Activity Guidelines Advisory Committee Scientific Report. Washington, DC: US Department of Health and Human Services; 2018.

2. Office of Disease Prevention and Health Promotion, US Department of Health and Human Services. Healthy People 2020: Topics \& Objectives-Physical Activity. September 13, 2018. https://www. healthypeople.gov/2020/topics-objectives/topic/physical-activity. Accessed August 8, 2018.

3. US Department of Health and Human Services. Physical Activity Guidelines for Americans. 2nd ed. Washington, DC: US Department of Health and Human Services; 2018.

4. US Department of Health and Human Services. 2008 Physical Activity Guidelines for Americans. Washington, DC: US Department of Health and Human Services; 2008.

5. 2008 Physical Activity Guidelines Advisory Committee. Physical Activity Guidelines Advisory Committee Report, 2008. Washington, DC: US Department of Health and Human Services; 2008.

6. 2018 Physical Activity Guidelines Advisory Committee. 2018 Physical Activity Guidelines Advisory Committee Scientific Report. Part E. Washington, DC: US Department of Health and Human Services; 2018.

7. 2018 Physical Activity Guidelines Advisory Committee. 2018 Physical Activity Guidelines Advisory Committee Scientific Report. Supplemental Information. Washington, DC: US Department of Health and Human Services; 2018.

8. Torres A, Tennant B, Ribeiro-Lucas I, Vaux-Bjerke A, Piercy K, Bloodgood B. Umbrella and systematic review methodology to support the 2018 physical activity guidelines advisory committee. J Phys Act Health. 2018;15(11):805-810. PubMed ID: 30336718 doi:10.1123/jpah.2018-0372

9. Johnson BT, MacDonald HV, Bruneau ML Jr, et al. Methodological quality of meta-analyses on the blood pressure response to exercise: a review. J Hypertens. 2014;32(4):706-723. PubMed ID: 24463936 doi:10.1097/HJH.0000000000000097

10. Shea BJ, Grimshaw JM, Wells GA, et al. Development of AMSTAR: a measurement tool to assess the methodological quality of systematic reviews. BMC Med Res Methodol. 2007;7:10. PubMed ID: 17302989 doi:10.1186/1471-2288-7-10

11. 2015 Dietary Guidelines Advisory Committee. 2015 Dietary Guidelines Advisory Committee Scientific Report. Nutrition Evidence Library Methodology. Washington, DC: US Department of Health and Human Services and US Department of Agriculture; 2015.

12. USDA NEL Tool-US Department of Agriculture. Nutrition Evidence Library-About. https://www.cnpp.usda.gov/nutrition-evidencelibrary-about. Accessed January 16, 2018.

13. 2018 Physical Activity Guidelines Advisory Committee. 2018 Physical Activity Guidelines Advisory Committee Scientific Report. Part F, Chapter 3. Washington, DC: US Department of Health and Human Services; 2018.

14. 2018 Physical Activity Guidelines Advisory Committee. 2018 Physical Activity Guidelines Advisory Committee Scientific Report. Part F, Chapter 9. Washington, DC: US Department of Health and Human Services; 2018.

15. 2018 Physical Activity Guidelines Advisory Committee. 2018 Physical Activity Guidelines Advisory Committee Scientific Report. Part F, Chapter 10. Washington, DC: US Department of Health and Human Services; 2018.

16. Chaddock-Heyman L, Erickson KI, Chappell MA, et al. Aerobic fitness is associated with greater hippocampal cerebral blood flow in children. Dev Cogn Neurosci. 2016;20:52-58. PubMed ID: 27419884 doi:10.1016/j.den.2016.07.001

17. Erickson KI, Voss MW, Prakash RS, et al. Exercise training increases size of hippocampus and improves memory. Proc Natl Acad Sci USA. 2011;108(7):3017-3022. PubMed ID: 21282661 doi:10.1073/pnas. 1015950108

18. Maass A, Duzel S, Brigadski T, et al. Relationships of peripheral IGF-1, VEGF and BDNF levels to exercise-related changes in memory, hippocampal perfusion and volumes in older adults. NeuroImage. 2016;131:142-154. PubMed ID: 26545456 doi:10.1016/j. neuroimage.2015.10.084

19. Colcombe SJ, Erickson KI, Scalf PE, et al. Aerobic exercise training increases brain volume in aging humans. J Gerontol A Biol Sci Med Sci. 2006;61(11):1166-1170. PubMed ID: 17167157 doi:10.1093/ gerona/61.11.1166

20. Sexton CE, Betts JF, Demnitz N, Dawes H, Ebmeier KP, JohansenBerg H. A systematic review of MRI studies examining the relationship between physical fitness and activity and the white matter of the ageing brain. NeuroImage. 2016;131:81-90. PubMed ID: 26477656 doi:10.1016/j.neuroimage.2015.09.071

21. Kredlow MA, Capozzoli MC, Hearon BA, Calkins AW, Otto MW. The effects of physical activity on sleep: a meta-analytic review. J Behav Med. 2015;38(3):427-449. PubMed ID: 25596964 doi:10. 1007/s10865-015-9617-6

22. 2018 Physical Activity Guidelines Advisory Committee. 2018 Physical Activity Guidelines Advisory Committee Scientific Report. Part F, Chapter 5. Washington, DC: US Department of Health and Human Services; 2018.

23. 2018 Physical Activity Guidelines Advisory Committee. 2018 Physical Activity Guidelines Advisory Committee Scientific Report. Part F, Chapter 7. Washington, DC: US Department of Health and Human Services; 2018.

24. 2018 Physical Activity Guidelines Advisory Committee. 2018 Physical Activity Guidelines Advisory Committee Scientific Report. 
Part F, Chapter 8. Washington, DC: US Department of Health and Human Services; 2018.

25. Rosenberg L, Kipping-Ruane KL, Boggs DA, Palmer JR. Physical activity and the incidence of obesity in young African-American women. Am J Prev Med. 2013;45(3):262-268. PubMed ID: 23953351 doi:10.1016/j.amepre.2013.04.016

26. Moore SC, Patel AV, Matthews CE, et al. Leisure time physical activity of moderate to vigorous intensity and mortality: a large pooled cohort analysis. PLoS Med. 2012;9(11):e1001335. PubMed ID: 23139642 doi:10.1371/journal.pmed.1001335

27. Hupin D, Roche F, Gremeaux V, et al. Even a low-dose of moderateto-vigorous physical activity reduces mortality by $22 \%$ in adults aged $\geq 60$ years: a systematic review and meta-analysis. Br J Sports Med. 2015;49(19):1262-1267. PubMed ID: 26238869 doi:10.1136/ bjsports-2014-094306

28. Sattelmair J, Pertman J, Ding EL, Kohl HW 3rd, Haskell W, Lee IM. Dose response between physical activity and risk of coronary heart disease: a meta-analysis. Circulation. 2011;124(7):789-795. PubMed ID: 21810663 doi:10.1161/CIRCULATIONAHA.110. 010710

29. 2018 Physical Activity Guidelines Advisory Committee. 2018 Physical Activity Guidelines Advisory Committee Scientific Report. Part F, Chapter 6. Washington, DC: US Department of Health and Human Services; 2018.

30. 2018 Physical Activity Guidelines Advisory Committee. 2018 Physical Activity Guidelines Advisory Committee Scientific Report. Part F, Chapter 2. Washington, DC: US Department of Health and Human Services; 2018.

31. Ekelund U, Steene-Johannessen J, Brown WJ, et al. Does physical activity attenuate, or even eliminate, the detrimental association of sitting time with mortality? A harmonised meta-analysis of data from more than 1 million men and women. Lancet. 2016;388(10051): 1302-1310. doi:10.1016/S0140-6736(16)30370-1

32. Ayabe M, Aoki J, Kumahara H, Tanaka H. Age-related differences in daily physical activity divided by bout duration: preliminary findings in female convenience samples. J Sports Sci. 2012; 30(7):709-713. PubMed ID: 22401295 doi:10.1080/02640414. 2012.667878

33. Ayabe M, Kumahara H, Morimura K, Tanaka H. Epoch length and the physical activity bout analysis: an accelerometry research issue. BMC Res Notes. 2013;6:20. PubMed ID: 23331772 doi:10.1186/ 1756-0500-6-20

34. Cameron N, Godino J, Nichols JF, Wing D, Hill L, Patrick K. Associations between physical activity and BMI, body fatness, and visceral adiposity in overweight or obese Latino and non-Latino adults. Int J Obes. 2017;41(6):873-877. doi:10.1038/ ijo.2017.49

35. Clarke J, Janssen I. Sporadic and bouted physical activity and the metabolic syndrome in adults. Med Sci Sports Exerc. 2014;46(1): 76-83. PubMed ID: 23846157 doi:10.1249/MSS.0b013e31829f83a0

36. Di Blasio A, Bucci I, Ripari P, et al. Lifestyle and high density lipoprotein cholesterol in postmenopause. Climacteric. 2014; 17(1):37-47. PubMed ID: 23249128 doi:10.3109/13697137.2012. 758700

37. Fan JX, Brown BB, Hanson H, Kowaleski-Jones L, Smith KR, Zick CD. Moderate to vigorous physical activity and weight outcomes: does every minute count? Am J Health Promot. 2013; 28(1):41-49. PubMed ID: 23458375 doi:10.4278/ajhp.120606QUAL-286

38. Gay JL, Buchner DM, Schmidt MD. Dose-response association of physical activity with HbA1c: intensity and bout length. Prev Med.
2016;86:58-63. PubMed ID: 26827616 doi:10.1016/j.ypmed.2016. 01.008

39. Glazer NL, Lyass A, Esliger DW, et al. Sustained and shorter bouts of physical activity are related to cardiovascular health. Med Sci Sports Exerc. 2013;45(1):109-115. PubMed ID: 22895372 doi:10.1249/ MSS.0b013e31826beae5

40. Jefferis BJ, Parsons TJ, Sartini C, et al. Does duration of physical activity bouts matter for adiposity and metabolic syndrome? A cross-sectional study of older British men. Int J Behav Nutr Phys Act. 2016;13:36. PubMed ID: 26980183 doi:10.1186/s12966-0160361-2

41. Loprinzi PD, Cardinal BJ. Association between biologic outcomes and objectively measured physical activity accumulated in $\geq 10$ minute bouts and <10-minute bouts. Am J Health Promot. 2013; 27(3):143-151. PubMed ID: 23286590 doi:10.4278/ajhp.110916QUAN-348

42. Strath SJ, Holleman RG, Ronis DL, Swartz AM, Richardson CR. Objective physical activity accumulation in bouts and nonbouts and relation to markers of obesity in US adults. Prev Chronic Dis. 2008;5(4):A131. PubMed ID: 18793519

43. Vasankari V, Husu P, Vähä-Ypyä H, et al. Association of objectively measured sedentary behaviour and physical activity with cardiovascular disease risk. Eur J Prev Cardiol. 2017;24(12):1311-1318. PubMed ID: 28530126 doi:10.1177/2047487317711048

44. White DK, Gabriel KP, Kim Y, Lewis CE, Sternfeld B. Do short spurts of physical activity benefit cardiovascular health? The CARDIA study. Med Sci Sports Exerc. 2015;47(11):2353-2358. PubMed ID: 25785930 doi:10.1249/MSS.0000000000000662

45. Wolff-Hughes DL, Fitzhugh EC, Bassett DR, Churilla JR. Total activity counts and bouted minutes of moderate-to-vigorous physical activity: relationships with cardiometabolic biomarkers using 2003-2006 NHANES. J Phys Act Health. 2015;12(5):694700. PubMed ID: 25109602 doi:10.1123/jpah.2013-0463

46. 2018 Physical Activity Guidelines Advisory Committee. 2018 Physical Activity Guidelines Advisory Committee Scientific Report. Part F, Chapter 1. Washington, DC: US Department of Health and Human Services; 2018.

47. 2018 Physical Activity Guidelines Advisory Committee. 2018 Physical Activity Guidelines Advisory Committee Scientific Report. Part F, Chapter 11. Washington, DC: US Department of Health and Human Services; 2018.

48. Buchholz SW, Wilbur J, Ingram D, Fogg L. Physical activity text messaging interventions in adults: a systematic review. Worldviews Evid Based Nurs. 2013;10(3):163-173. PubMed ID: 23746267 doi:10.1111/wvn.12002

49. Goode AD,Reeves MM, Eakin EG. Telephone-delivered interventions for physical activity and dietary behavior change: an updated systematic review. Am J Prev Med. 2012;42(1):81-88. PubMed ID: 22176852 doi:10.1016/j.amepre.2011.08.025

50. Chu AH, Ng SH, Tan CS, Win AM, Koh D, Müller-Riemenschneider F. A systematic review and meta-analysis of workplace intervention strategies to reduce sedentary time in white-collar workers. Obes Rev. 2016;17(5):467-481. PubMed ID: 26990220 doi:10.1111/obr. 12388

51. Morris JN. Exercise in the prevention of coronary heart disease: today's best buy in public health. Med Sci Sports Exerc. 1994; 26(7):807-814. PubMed ID: 7934752 doi:10.1249/00005768199407000-00001

52. Center for Disease Control and Prevention. National Health Interview Survey. November 3, 2017. https://www.cdc.gov/nchs/nhis/nhis_ 2015_data_release.htm. Accessed January 11, 2018. 
53. Institute of Medicine. Progress in Preventing Childhood Obesity: How Do We Measure Up? Washington, DC: The National Academies Press; 2007.

54. Centers for Disease Control and Prevention. Deaths and Mortality. May 3, 2017. https://www.cdc.gov/nchs/fastats/deaths.htm. Accessed July 3, 2018.

55. Lyubomirsky S, King L, Diener E. The benefits of frequent positive affect: does happiness lead to success? Psychol Bull. 2005; 131(6):803-855. PubMed ID: 16351326 doi:10.1037/0033-2909. 131.6 .803
56. Agency for Healthcare Research and Quality. Big Money: Cost of 10 Most Expensive Health Conditions near \$500 Billion. https://archive. ahrq.gov/news/nn/nn012308.htm. Accessed May 21, 2018.

57. Gerteis J, Izrael D, Deitz D, et al. Multiple Chronic Conditions Chartbook. AHRQ Publications No, Q14-0038. Rockville, MD: Agency for Healthcare Research and Quality; 2014.

58. Harrison PL, Pope JE, Coberley CR, Rula EY. Evaluation of the relationship between individual well-being and future health care utilization and cost. Popul Health Manag. 2012;15(6):325-330. PubMed ID: 22356589 doi:10.1089/pop.2011.0089 